\title{
Influence of chemical degradation and abrasion on surface properties of nanorestorative materials
}

\author{
Andréia Bolzan de Paula ${ }^{1}$, Roberta Caroline Bruschi Alonso² ${ }^{2}$ Giovana Albamonte Spagnolo de Araújoㄹ, \\ Julia Puppin Rontani ${ }^{1}$, Lourenço Correr-Sobrinho ${ }^{1}$, Regina Maria Puppin-Rontani ${ }^{3}$
}

${ }^{1}$ Universidade Estadual de Campinas - UNICAMP, Piracicaba Dental School, Area of Dental Materials, Piracicaba, SP, Brazil
${ }^{2}$ Faculdade Anhanguera, Dental School, Area of Biomaterials, São Paulo, SP, Brazil
${ }^{3}$ Universidade Estadual de Campinas - UNICAMP, Piracicaba Dental School, Area of Pediatric Dentistry, Piracicaba, SP, Brazil

Abstract

Received for publication: March 04, 2015 Accepted: May 22, 2015

Correspondence to: Andreia Bolzan de Paula Universidade Estadual de Campinas Faculdade de Odontologia de Piracicaba Departamento de Odontologia Restauradora Av. Limeira, 901 CEP: 13414-903 Piracicaba, SP, Brasil Phone: +55 1921065286 / Fax: +55 1921065218 E-mail: andbol_63@hotmail.com
Aim: The aim of this in vitro study was to investigate the synergistic effect of chemical degradation (erosion) and three-body abrasion (mechanical degradation) on the surface roughness (Ra) and hardness $(\mathrm{KHN})$ of two nanorestorative materials and two conventional materials. Methods: Discshaped specimens ( $5 \mathrm{~mm}$ in diameter, $2 \mathrm{~mm}$ thick) of Filtek $Z 350^{\mathrm{TM}}$ and TPH Spectrum ${ }^{\mathrm{TM}}$ composites and Ketac $\mathrm{Nano}^{\mathrm{TM}}$ and Vitremer ${ }^{\mathrm{TM}}$ light-curing glass ionomer cements, nanomaterials and conventional materials were prepared according to the manufacturer's instructions. After $24 \mathrm{~h}$, polishing procedures were performed and initial measurements of Ra and KHN were taken in all specimens. The specimens were divided into 12 groups $(n=10)$ according to material and storage media: artificial saliva, orange juice, and Coca-Cola $\circledast$. After 30 days of storage, the specimens were submitted to mechanical degradation and re-evaluated for Ra and KHN. Data were tested for significant differences by repeated-measure three-way ANOVA and Tukey's tests $(p<0.05)$. Results: Erosion and abrasion wear significantly decreased hardness of all materials. Only Filtek Z350 roughness, however, was not affected by erosion and abrasion. All materials showed a significant increase in surface roughness after erosion and abrasion, except for Filtek Z350. After chemical and mechanical degradation, the KHN of all samples had decreased significantly. After mechanical degradation, the acidic drinks (Coca-Cola ${ }^{\circledR}$ and orange juice) were more aggressive than artificial saliva to all materials. Conclusions: A synergistic effect was observed by the increase in roughness for all materials, except for Filtek Z350; hardness values decrease for all materials, regardless of whether they were nanofilled or not. The RMGICs were more susceptible to degradation than the composites, considering both hardness and roughness surface parameters.

Keywords: nanotechnology; tooth erosion; tooth abrasion.

\section{Introduction}

The application of nanotechnology to dental materials was introduced in past few decades. In addition to improved optical properties, nanomaterials present better mechanical behavior ${ }^{1}$, since the nanometric size of particle allows incorporating greater amount of filler load in the restorative materials ${ }^{2}$. Nanofillers and nanofiller "clusters" are combined to improve mechanical properties, as threebody wear resistance. The nanofiller components also provide superior aesthetics and excellent polishing, with higher gloss and smoother surfaces than other resin- 
modified glass ionomers (RMGICs), while offering fluoride release similar to that of a conventional RMGIC.

A new RMGIC has been introduced for operative dentistry recently: Ketac Nano. This material contains nanofillers and clusters of nano-sized zirconia/silica that result in a highly packed filler composition. It is important to compare this material to a traditional RMGIC and a nanocomposite in order to establish whether the nano-ionomer shows a behavior similar to that of ionomeric and composite materials, thus predicting its mechanical and chemical properties.

Although it is possible to improve the material physical properties by incorporating nanofillers into restorative materials, it should be considered that the restorative materials are constantly subject to thermal, mechanical, and chemical challenges on the oral environment. De Paula et al. ${ }^{3}$ (2011) found that nanotechnology incorporated in restorative materials, is important for the superior resistance to biomechanical degradation.

Those challenges can negatively influence the material properties by causing degradation of the matrix in resin influences the degradation of resin composites and glassionomer restorative materials ${ }^{4}$. Soft drinks may contain several different types of acid that contribute to their low $\mathrm{pH}$ value ${ }^{5}$. A study reported by Jensdottir et al. ${ }^{6}$ (2004) have found carbonated drinks, especially carbonated cola drinks, to be associated with erosion. An in vitro study has shown, however, that fruit juices may also be erosive, due their high titrability? The erosive attack can induce matrix and filler degradation of restorative materials, and also potentially jeopardize the clinical performance of these materials ${ }^{8}$. Not only erosive attack can jeopardize the restorative materials surface, but also the abrasion process produced by oral hygiene methods can adversely affect the surface characteristics of restorative materials ${ }^{1}$. This process may interfere with both health and aesthetics, since rough surfaces may predispose teeth to biofilm accumulation. De Paula et al. ${ }^{3}$ (2011) have found that nanomaterials, when exposed to a cumulative effect of biofilm/ abrasion, shows superior resistance to biomechanical degradation in comparison with conventional restorative materials. It may therefore, be hypothesized that toothbrush abrasion and erosion caused by an acidic diet have a synergic effect on the substance loss of dental materials.

In this way, restorative materials are in a constant process of degradation in the oral cavity, and nanotechnology has been investigated for its possible application to the materials as a way to minimize the cumulative deleterious effects of this process. The aim of this in vitro study was to investigate the synergistic effect of chemical degradation (erosion) and three-body abrasion (mechanical degradation) on the surface roughness $(\mathrm{Ra})$ and hardness $(\mathrm{KHN})$ of two nanomaterials and two conventional materials.

\section{Material and methods}

\section{Specimen Preparation and Initial Analysis}

Four different types of tooth-colored restorative materials were tested in this study (Table 1): two RMGICs (Vitremer and Ketac Nano, 3M ESPE, St. Paul, MN, USA) and two composites: Filtek Z350 (3M ESPE), and TPH Spectrum (Dentsply, Caulk, USA). Thirty specimens of each material were manipulated according to the manufacturer's instructions. Materials were inserted into plastic molds with internal dimensions of $5 \mathrm{~mm}$ diameter and $2 \mathrm{~mm}$ thickness. The top surface of the fulfilled mold was covered by a polyester strip and pressed flat by a glass slab. The top surface of all materials was cured according to the manufacturer's cure times using an Elipar Trilight curing light unit $(3 \mathrm{M}$ ESPE), with a mean light intensity of about $800 \mathrm{~mW} / \mathrm{cm}^{2}$

Table 1. Materials tested in this study.

\begin{tabular}{|c|c|c|c|}
\hline Materials & Composition & $\begin{array}{l}\text { Mean Filler Size } \\
\qquad(\mu \mathrm{m})\end{array}$ & $\begin{array}{c}\text { Manufacturer/Batch } \\
\#\end{array}$ \\
\hline $\begin{array}{l}\text { Ketac }^{\text {TM Nano }} \\
(3 \mathrm{M} \text { ESPE) }\end{array}$ & $\begin{array}{l}\text { Paste A: silane-treated glass, silane-treated zirconia oxide silica, polyethylene glycol } \\
\text { dimethacrylate (5-15\%), silane-treated silica, HEMA, Bis-GMA }(<5 \%) \text {, TEGDMA }(< \\
\text { 5\%), HEMA (1-10\%)Paste B: silane-treated ceramic, silane-treated silica, copolymer of } \\
\text { acrylic and itaconic acids, HEMA (1-10\%) }\end{array}$ & $5-25 \mathrm{~nm}$ & $\begin{array}{l}\text { 3M-ESPE, St. Paul, } \\
\text { MN, USA } \\
\text { M3M3 }\end{array}$ \\
\hline $\begin{array}{l}\text { Vitremer } \\
(3 \mathrm{M} \text { ESPE) }\end{array}$ & $\begin{array}{l}\text { Powder: fluoroaluminosilicate glass; redox systemLiquid: aqueous solution of a modified } \\
\text { polyalkenoic acid, HEMA (15-20\%) }\end{array}$ & $3.0 \mu \mathrm{m}$ & $\begin{array}{l}\text { 3M-ESPE, St. Paul, } \\
\text { MN, USA } \\
\text { P: } 6 \mathrm{LP} \\
\text { L: } 6 \mathrm{FH}\end{array}$ \\
\hline $\begin{array}{l}\text { Filtek Z350 } \\
\text { (3M ESPE) }\end{array}$ & $\begin{array}{l}\text { 58-60 vol. \% ( } 78.5 \text { wt. \%) combination of aggregated zirconia/silica cluster filler with } \\
\text { primary particles size of } 5-20 \mathrm{~nm} \text {, and non-agglomerated } 20 \mathrm{~nm} \text { silica filler, Bis-EMA, } \\
\text { Bis-GMA; UDMA; TEGDMA }\end{array}$ & $\begin{array}{l}5-20 \mathrm{~nm} \\
0.6-1.4 \mu \mathrm{m} \\
\text { (clusters) }\end{array}$ & $\begin{array}{l}\text { 3M-ESPE, St. Paul, } \\
\text { MN, USA } \\
\text { 8NU }\end{array}$ \\
\hline $\begin{array}{l}\text { TPH Spectrum } \\
\text { (Dentsply) }\end{array}$ & $\begin{array}{l}\text { Polymer matrix: Bis-GMA, Bis-EMA and TEGDMA; Filler: } 57 \text { vol\% of Ba-Al-borosilicate } \\
\text { glass and colloidal silica with mean particle size of } 0.8 \mu \mathrm{m}\end{array}$ & $0.8 \mu \mathrm{m}$ & $\begin{array}{l}\text { Dentsply Ind. E Com. Ltd., } \\
\text { Petropolis, RJ, } \\
\text { BrazilL797977 }\end{array}$ \\
\hline
\end{tabular}

Bis-GMA = bisphenol glycidyl methacrylate; TEGDMA = triethylene glycol dimethacrylate; HEMA = 2hydroxyethyl methacrylate; Bis-EMA = ethoxylated bisphenol-A dimethacrylate; UDMA = urethane dimethacrylate. 
checked with a curing light meter (Hilux Dental Curing Light Meter, Benliglu Dental Inc., Turkey). The surface of Vitremer was protected with Finishing Gloss (3M ESPE).

All specimens were maintained at $100 \%$ relative humidity and $37{ }^{\circ} \mathrm{C}$ for $24 \mathrm{~h}$. Then, the surfaces were wetpolished with on a sequence of waterproofed silicon carbide paper (600-, 1200-, and 2000-grit) and ultrasonically cleaned (Ultrasonic Cleaner, model USC1400, Unique Co, São Paulo, $\mathrm{SP}$, Brazil) in distilled water for 10 minutes to remove polishing debris. The specimens were randomly distributed into 12 groups $(n=10)$, according to material and storage medium: artificial saliva (control), orange juice (Minute Maid, Coca-Cola), and Coca-Cola ${ }^{\circledR}$ (Table 2).

Before erosion testing, specimens were analyzed for surface roughness and Knoop hardness. For surface roughness testing, the specimens were analyzed using a Surfcorder SE1700 instrument (Kosaka Corp, Tokyo, Japan), with cutoff length of $0.25 \mathrm{~mm}$, at a tracing speed of $0.1 \mathrm{~mm} / \mathrm{s}$. The mean surface roughness values ( $\mathrm{Ra}, \mathrm{mm})$ of each specimen were obtained from three successive measurements of the center of each disk in different directions (total length analyzed of $3.750 \mathrm{~mm})^{9}$. Then, hardness tests were carried out by a Knoop indenter (Shimatzu, Tokyo, Japan) and a $50 \mathrm{~g}$ load, $15 \mathrm{~s}$ dwell time. Three readings were taken for each specimen, and the mean KHN was calculated.

\section{Erosion - Storage in acidic drinks}

All specimens were immersed individually in $4 \mathrm{~mL}$ of storage solutions: Coca-Cola ${ }^{\circledR}(\mathrm{pH} 2.49)$, orange juice $(\mathrm{pH}$ 3.23 ) and artificial saliva ( $\mathrm{pH} 7.00$ ), for 30 days. The solutions were weekly changed and $\mathrm{pH}$-tested by a portable $\mathrm{pH}$ meter (Orion Model 420A, Analyzer, São Paulo, SP, Brazil). In all cases, the $\mathrm{pH}$ electrodes were calibrated immediately before use, by standard buffer solutions at $\mathrm{pH} 4.0$ and 7.0. At the end of the storage period, the specimens were ultrasonically washed for $10 \mathrm{~min}$.

\section{Three-body Abrasion Test}

After erosion, the tooth-brushing test was performed in all specimens at $250 \mathrm{cycles} / \mathrm{min}$, for 30,000 cycles with a 200 g load. Colgate Total dentifrice (Colgate Palmolive Co., São Bernardo do Campo, São Paulo, Brazil) diluted in distilled water (1:2) was used as an abrasive third body. The specimens were ultrasonically washed for $10 \mathrm{~min}$, then dried and evaluated for roughness and hardness. Surface roughness readings were made on each specimen perpendicular to the brushing movement ${ }^{10}$.

\section{Statistical analysis}

Data were evaluated by the PROC LAB from SAS in order to check the equality of variances and confirm a normal distribution. Hardness and roughness data were submitted to repeated-measure three-way ANOVA and Tukey's test with a significance level of $5 \%$.

\section{Results}

Regarding roughness, there was significant interaction between the factors "materials" and "erosion/abrasion effect" $(\mathrm{p}<0.0001)$, and also between "storage solution" and "erosion effect" $(\mathrm{p}<0.0001)$. There was a significant difference among the three factors $(p<0.0001)$. It was not observed any significant interaction between "materials" and "storage solution" $(\mathrm{p}=0.2372)$. The means and standard deviations of surface roughness of each material after erosive/ abrasive challenge are presented in Table 3 .

Regardless of the storage solution, both composites (Filtek Z350 and TPH Spectrum) presented similar roughness values $(p>0.05)$ and significantly lower roughness values than glass ionomer cements, both before and after erosive challenge/abrasion. There was no significant difference in roughness values between Ketac Nano and Vitremer, in all storage conditions $(p>0.05)$. In addition, when different storage solutions were compared concerning each material after erosive challenge and abrasion, it was observed that there was no statistically significant difference in surface roughness for TPH composite. However, the orange juice was more aggressive than the artificial saliva for Filtek Z350, Ketac Nano, and Vitremer, increasing the surface roughness. In all cases, however, the cumulative effect of erosive challenge plus abrasion roughened the specimens of all materials, except the Filtek Z350 surface.

Table 4 shows the means and standard deviations of the Knoop hardness of each material after erosive/abrasive challenge. There was significant interaction among the three factors $(p=0.0062)$. There was no significant interaction between the factors "materials" and "storage solution" $(p=0.6294)$, or between "materials" and "erosion/abrasion

Table 2. Main characteristics of the storage solutions studied

\begin{tabular}{|c|c|c|}
\hline Food/Drink & Main Ingredients & $\mathrm{pH}$ \\
\hline Coca-Cola ${ }^{8}$ & Carbonated water, sugar, caramel color, phosphoric acid, natural flavors, caffeine & 2.49 \\
\hline $\begin{array}{l}\text { Orange Juice } \\
\text { (Minute Maid } ® \text { ) }\end{array}$ & Water, orange juice, sugar, citric acid, natural flavor, antioxidant ascorbic acid & 3.23 \\
\hline Artificial Saliva & $\begin{array}{l}\text { Calcium ( } 0.1169 \mathrm{~g} \text { of calcium hydroxide/L of deionized water); } 0.9 \mathrm{mM} \text { of phosphorus and potassium } \\
(0.1225 \mathrm{~g} \text { potassium phosphate monobasic/L of deionized water); } 20 \mathrm{mM} \text { TRIS buffer ( } 2.4280 \mathrm{~g} \text { TRIS } \\
\text { buffer/L of deionized water) }\end{array}$ & 7.0 \\
\hline
\end{tabular}


Table 3. Surface roughness mean (standard deviation in parentheses) $(\mu \mathrm{m})$ of restorative materials submitted to erosion/abrasion challenge.

\begin{tabular}{lllcc}
\hline & \multicolumn{4}{c}{ Materials Storage Solutions } \\
Initial & TPH & $* 0.17(0.04) \mathrm{Ab}$ & ${ }^{*} 0.19(0.03) \mathrm{Ab}$ & $* 0.19(0.04) \mathrm{Ab}$ \\
& Filtek Z350 & $0.12(0.05) \mathrm{Ab}$ & $0.13(0.03) \mathrm{Ab}$ & $0.12(0.03) \mathrm{Ab}$ \\
& Ketac Nano & ${ }^{*} 0.32(0.11) \mathrm{Aa}$ & ${ }^{*} 0.34(0.10) \mathrm{Aa}$ & $* 0.33(0.10) \mathrm{Aa}$ \\
& Vitremer & $* 0.45(0.15) \mathrm{Aa}$ & $* 0.43(0.13) \mathrm{Aa}$ & $* 0.41(0.09) \mathrm{Aa}$ \\
After erosion & TPH & $0.30(0.04) \mathrm{Ab}$ & $0.30(0.14) \mathrm{Ab}$ & $0.37(0.06) \mathrm{Ab}$ \\
and abrasion & Filtek Z350 & $0.13(0.02) \mathrm{Bb}$ & $0.16(0.02) \mathrm{ABb}$ & $0.23(0.08) \mathrm{Ab}$ \\
& Ketac Nano & $0.71(0.18) \mathrm{Ba}$ & $0.59(0.19) \mathrm{Ba}$ & $1.14(0.67) \mathrm{Aa}$ \\
& Vitremer & $0.63(0.20) \mathrm{Ba}$ & $0.74(0.13) \mathrm{Ba}$ & $1.58(0.82) \mathrm{Aa}$ \\
\hline
\end{tabular}

Capital letters indicate comparison among storage solutions (horizontal). Lowercase letters demonstrate comparison among materials (vertical) within each storage solution and each erosion condition (before or after). Asterisks represent a significant statistically difference between erosion effects (before and after). Groups denoted by the same letter/symbol represent no significant difference $(p>0.05)$.

Table 4. Knoop hardness mean (standard deviation in parentheses) (KHN) of restorative materials submitted to erosion/abrasion challenge.

\begin{tabular}{|c|c|c|c|c|}
\hline & & \multicolumn{3}{|c|}{ Materials Storage Solutions } \\
\hline & & Saliva & Coca-Cola & Juice \\
\hline \multirow[t]{4}{*}{ Initial } & $\mathrm{TPH}$ & *82.24 (11.15) Aa & *79.9 (9.11) Aa & *80.43(10.97)Aa \\
\hline & Filtek Z350 & *80.10 (8.2) Aa & *84.0(9.79)Aa & *83.5 (10.31) Aa \\
\hline & Ketac Nano & *41.8 (5.24) Ab & *40.5 (5.56) Ab & *39.8 (6.73) Ab \\
\hline & Vitremer & *39.8 (5.53) Ab & *40.51 (6.82) Ab & *40.31 (8.51) Ab \\
\hline \multirow{4}{*}{$\begin{array}{l}\text { After erosion } \\
\text { and abrasion }\end{array}$} & $\mathrm{TPH}$ & 67.54 (10.42) Aa & $58.33(4.88) \mathrm{Ba}$ & $66.75(4.38) \mathrm{Ba}$ \\
\hline & Filtek Z350 & $73.60(9.80) \mathrm{Aa}$ & $66.19(7.99) \mathrm{Ba}$ & $67.53(6.60) \mathrm{Ba}$ \\
\hline & Ketac Nano & $38.78(6.47) \mathrm{Ab}$ & $29.20(4.98) \mathrm{Bb}$ & $29.20(4.34) \mathrm{Bb}$ \\
\hline & Vitremer & 31.55 (8.07) Ab & $25.95(4.79) \mathrm{Bb}$ & $25.74(4.73) \mathrm{Bb}$ \\
\hline
\end{tabular}

Capital letters indicate comparison among storage solutions (horizontal). Lowercase letters demonstrate comparison among materials (vertical) within each storage solution and each erosion condition (before or after). Asterisks represent a significant statistically difference between erosion effects (before and after). Groups denoted by the same letter/symbol represent no significant difference $(p>0.05)$.

effect" $(p<0.0665)$. Between "storage solution" and "erosion and abrasion effect" $(p<0.0001)$, however, there was significant interaction. In addition, there was significant difference among materials studied $(\mathrm{p}<0.0001)$, among storage solutions (saliva/juice/Coca-Cola $\left.{ }^{\circledR} ; \mathrm{p}<0.0177\right)$, and between erosion/abrasion effects $(p<0.0001)$.

Before erosion/abrasion challenge, it was observed that both composites (Filtek Z350 and TPH Spectrum) presented similar or significantly higher values than the RMGICs, which also presented similar values between them. Regarding erosion/abrasion effects on each material' surface, exposure to any storage solutions produced significantly lower hardness values for all materials tested. It was also observed that the storage solution influenced the materials: The acidic drinks (Coca-Cola ${ }^{\circledR}$ and orange juice) were more aggressive than artificial saliva to all materials. In addition, composites presented significantly higher hardness values than ionomeric materials after chemical/abrasion degradation.

\section{Discussion}

Wear of a dental material involves various processes, such as abrasion and erosion. On exposure to dental biofilm acids, food-simulating constituents and enzymes, resin-based restorative materials can be softened. Consumption of certain beverages, such as coffee, tea, soft drinks, fruit juices, and alcoholic beverages, may affect the aesthetics and physical properties of composite resins ${ }^{11}$.

Usually after consuming beverages and foods, people brush their teeth to prevent caries development, exerting mechanical forces on enamel/restorative material surface ${ }^{12}$. The wear resistance of composites and RMGIC is greatly influenced by the size and shape of the filler particles. According to De Paula et al. $^{3}(2011)$ and de Fúcio et al. ${ }^{13}$ (2012), the greater the size of filler particles, the greater the amount of material lost.

This study evaluated the cumulative effect of erosion and abrasion in composites and RMGIC. Higher roughness values were observed for RMGIC than for composite resins before the erosion/abrasion challenge. The differences observed at baseline among materials regarding their means of surface roughness are mainly related to differences in their filler particle size, shape, volume, and distribution, and to their interaction with the organic matrix, allowing better polishing characteristics for the composites ${ }^{14}$. Also, those results may be occurred through the handling of RMGICs, since they are in a powder: liquid or paste: paste formulation 
and air can be trapped in the material structure, resulting in surface bubbles and exposure of porosities after finishing/ polishing procedures.

Similar roughness values between the nanofilled and conventional materials were observed before erosion/abrasion challenge, for both the composite and RMGIC groups. Cavalcante et al. ${ }^{15}$ (2009) have demonstrated, however, that nanofilled composites present lower roughness values and better polishing characteristics than do hybrid composites, thanks to the presence of nanofillers. Most likely, the resinous matrix of the materials used in this study was not totally removed by initial finishing/polishing procedures, leaving a matrix layer over the fillers.

The erosive/abrasive challenge affected surface roughness of TPH Spectrum, but it was observed that there was no statistically significant difference in surface roughness for TPH composite, concerning storage solutions. The ethoxylated version of the Bis-GMA (Bis-EMA) existing in the composition of TPH Spectrum matrixes probably contributed to their hydrolytic and biochemical stability, by the hydrophobicity of this monomer. Yap et al. ${ }^{16}$ (2000) have also showed that the surface roughness of a Bis-EMAbased composite is not affected by acidic beverages. BisEMA shows a decreased flexibility and increased hydrophobicity due to the elimination of the hydroxyl groups, when compared with composites formulated with Bis-GMA ${ }^{17}$. Hence, the reduction in water uptake may be partially responsible for the chemical stability of composites that contain Bis-EMA.

For the other materials (Filtek Z350, Ketac Nano, and Vitremer), orange juice resulted in higher surface roughness values than did saliva and Coca-Cola ${ }^{\circledR}$, indicating that solutions produced different effects in materials. There are two ways to quantify the acid content of a beverage include $\mathrm{pH}$ and total or titrable acidity. Barbour and Shellis ${ }^{18}$ (2007) have shown that fruit juices may also be potentially erosive, because of their high content of titrable acid. It was shown that, the higher the value of titrable acidity, the greater were the erosion effects. Coca-Cola ${ }^{\circledR}$ contains phosphoric acid that has low titratiability, and has been shown to contain almost no carboxylic acid.

Only Filtek Z350 specimens retained similar roughness values before and after erosion and abrasion challenge. The biomechanical degradation resistance of nanocomposite Filtek Z350 is basically related to its chemical composition. With regard to filler particles, this material is formulated by a combination of nanosized particles with the nanocluster formulations ${ }^{18}$. The higher filler loading with smaller particle size provides a reduction in the interstitial spacing, which effectively protects the softer matrix, reduces the incidence of filler exfoliation, and enhances the material's overall resistance to abrasion ${ }^{19}$. When the nanocomposite undergoes toothbrush abrasion, only nanosized particles are plucked away, leaving the surfaces with defects smaller than light wavelength ${ }^{1}$.

Another parameter used in this study to measure the surface changes caused by erosion/abrasion was Knoop hardness. According to the present results, both composites
(Filtek Z350 and TPH Spectrum) presented higher hardness values than the RMGICs before and after the erosion/abrasion challenge. The different constitution of organic matrices and higher filler loading, could explain the behavior of these materials. In addition, the initial characteristics of hardness are not affected by the presence of nanofillers in the different materials studied.

After erosion/abrasion, all materials showed a significant reduction of hardness for all storage solutions. This reduction appears to have originated from hydrolysis ${ }^{20}$. According to $\operatorname{Sarkar}^{21}$ (2000), corrosive wear begins with water absorption that diffuses internally through the resin matrix, filler interfaces, pores, and other defects, accelerated by the solution's low $\mathrm{pH}$. Moreover, the RMGICs showed a greater loss of hardness than the resin composites after erosion/ abrasion. Thus, the chemical degradation rates of different materials depend on their hydrolytic stabilities, which are mainly related to the resin matrix. As the resin matrix of composites is known to absorb a small percentage of water ${ }^{22}$, composites were more degradation-resistant than hydrophilic materials, such as RMGICs ${ }^{23}$. In addition, the storage solutions may promote dissolution near the glass particles, which could be the result of dissolution of the siliceous hydrogel layer of RMGICs $^{24}$. On the other hand, the acid could also attack the resin (to a lesser extent), softening the methacrylate-based polymers, possibly by leaching the comonomers, such as triethylene glycol dimethacrylate (TEGDMA), and thus decreasing the surface hardness of these materials ${ }^{4}$. This process is also emphasized by abrasion challenge ${ }^{15}$. Abrasion commonly takes place through a gradual removal of the softened organic material. This removal eventually leaves the fillers unsupported and susceptible to exfoliation ${ }^{25}$, which may have had a part in reducing the hardness of all the materials.

It can be concluded that, according to the chemical composition of the material and storage medium, a synergistic effect can be observed by the increase in roughness for all materials used, except for Filtek Z350; hardness values decreased for all materials, regardless of whether they were nanofilled. RMGIC is more susceptible to degradation than are composites, in both hardness and roughness surface parameters.

This study showed that restorative materials might undergo degradation when exposed to acidic solutions and abrasive wear. However, an in vitro study presents some limitations, and thus in vivo studies should be performed to confirm these results in the oral environment.

\section{References}

1. Schmidt C, llie N. The effect of aging on the mechanical properties of nanohybrid composites based on new monomer formulations. Clin Oral Investig. 2013; 17: 251-7.

2. Senawongse P, Pongprueksa P. Surface roughness of nanofill and nanohybrid resin composites after polishing and brushing. J Esthet Restor Dent. 2007; 19: 265-73.

3. de Paula AB, Fucio SB, Ambrosano GM, Alonso RC, Sardi JC, PuppinRontani RM. Biodegradation and abrasive wear of nano restorative materials. Oper Dent. 2011; 36: 670-7. 
4. Asmussen E. Softening of Bis-GMA-based polymers by ethanol and by organic acids of plaque. Scand J Dent Res. 1984; 92: 257-61.

5. Edwards M, Creanor SL, Foye RH, Gilmour WH. Buffering capacities of soft drinks: the potential influence on dental erosion. J Oral Rehabil. 1999; 26: 923-7.

6. Jensdottir T, Arnadottir IB, Thorsdottir I, Bardow A, Gudmundsson K, Theodors A, et al. Relationship between dental erosion, soft drink consumption, and gastroesophageal reflux among Icelanders. Clin Oral Investig. 2004; 8: 91-6.

7. Jensdottir T, Bardow A, Holbrook P. Properties and modification of soft drinks in relation to their erosive potential in vitro. J Dent. 2005; 33: 569-75.

8. Francisconi LF, Honório HM, Rios D, Magalhães AC, Machado MA, Buzalaf MA. Effect of erosive $\mathrm{pH}$ cycling on different restorative materials and on enamel restored with these materials. Oper Dent. 2008; 33: 203-8.

9. Lopes MB, Saquy PC, Moura SK, Wang L, Graciano FM, Correr Sobrinho $L$, et al. Effect of different surface penetrating sealants on the roughness of a nanofiller composite resin. Braz Dent J. 2012; 23: 692-7.

10. Carvalho FG, Sampaio CS, Fucio SB, Carlo HL, Correr-Sobrinho L, Puppin-Rontani RM. Effect of chemical and mechanical degradation on surface roughness of three glass ionomers and a nanofilled resin composite. Oper Dent. 2012; 37: 509-17.

11. Seow LL, Chong SY, Lau MN, Tiong SG, Yew CC. Effect of beverages and food source on wear resistance of composite resins. Malaysian Dent J. 2008; 29: 34-9.

12. Addy M, Hunter ML. Can tooth brushing damage your health? Effects on oral and dental tissues. Int Dent J. 2003; 53: 177-86.

13. de Fúcio SB, de Paula AB, de Carvalho FG, Feitosa VP, Ambrosano GM, Puppin-Rontani RM. Biomechanical degradation of the nano-filled resin-modified glass-ionomer surface. Am J Dent. 2012; 25: 315-20.

14. Gladys S, Van Meerbeek B, Braem M, Lambrechts P, Vanherle G. Comparative physico-mechanical characterization of new hybrid restorative materials with conventional glass-ionomer and resin composite restorative materials. J Dent Res. 1997; 76: 883-94.

15. Cavalcante LM, Masouras K, Watts DC, Pimenta LA, Silikas N. Effect of nanofillers' size on surface properties after toothbrush abrasion. Am J Dent. 2009; 22: 60-4.

16. Yap AU, Low JS, Ong LF. Effect of food-simulating liquids on surface characteristics of composite and polyacid-modified composite restoratives. Oper Dent. 2000; 25: 170-6.

17. Wu W, McKinney JE. Influence of chemicals on wear of dental composites. J Dent Res. 1982; 61: 1180-3.

18. Barbour ME, Shellis RP. An investigation using atomic force microscopy nanoindentation of dental enamel demineralization as a function of undissociated acid concentration and differential buffer capacity. Phys Med Biol. 2007; 52: 899-910.

19. Turssi CP, Ferracane JL, Vogel K. Filler features and their effects on wear and degree of conversion of particulate dental resin composites. Biomaterials. 2005; 26: 4932-7.

20. Cilli R, Pereira JC, Prakki A. Properties of dental resins submitted to $\mathrm{pH}$ catalysed hydrolysis. J Dent. 2012; 40: 1144-50.

21. Sarkar NK. Internal corrosion in dental composite wear. J Biomed Mater Res. 2000; 53: 371-80.

22. Ferracane JL. Hygroscopic and hydrolytic effects in dental polymer networks. Dent Mater. 2006; 22: 211-22.

23. Mohan M, Shey Z, Vaidyanathan I, Vaidyanathan TK, Munisamy S, Janal M. Color changes of restorative materials exposed in vitro to cola beverage. Pediatr Dent. 2008; 30: 309-316.

24. Turssi CP, Hara AT, Serra MC, Rodrigues AL Jr. Effect of storage media upon the surface micromorphology of resin-based restorative materials. J Oral Rehabil. 2002; 29: 864-71.

25. Condon JR, Ferracane JL. In vitro wear of composite whit varied cure, filler level, and filler treatment. J Dent Res. 1997; 76: 1405-11. 